\title{
Evaluation of Water Resources Vulnerability in the Coastal Areas of the Yellow Sea and Bohai Sea under Seawater Intrusion-A case study of Longkou City, Shandong Province
}

\author{
Lei Qiu* , Ying Cao and Jingyi Huang \\ Institute of Management Science, Hohai University, Nanjing 210098, China.
}

\begin{abstract}
In view of the increased vulnerability of water resources system caused by seawater intrusion in the coastal areas of the Yellow Sea and Bohai Sea, this paper based on the VSD(Vulnerability Scoping Diagram) model to construct the water resource vulnerability evaluation index system of "exposure-sensitivity-adaptive capacity" under seawater intrusion. Then use entropy-TOPSIS method to evaluate water resource vulnerability and divide the levels. In addition, take Longkou City of Shandong Province as an example to conduct empirical research. The results show that the water resource vulnerability of Longkou City is at a strong vulnerability level. The water resources system is under obvious pressure. Population density, per capita GDP, temperature and precipitation change are the main factors of the system pressure. Seawater intrusion has a high degree of impact on water resources vulnerability and water resource system is more sensitive to groundwater level, chloride concentration and other stimuli. The improvement of water use efficiency and scientific and technological investment contribute to the significant enhancement of the adaptability of the water resources system of Longkou City.
\end{abstract}

\section{Introduction}

The coastal areas of the Yellow Sea and the Bohai Sea have an advantageous geographical location, rapid economic development, dense population, which leads to an increasing demand for water resources. According to the 2019 Beihai District Marine Disaster Bulletin, seawater intrusion is still relatively serious in the coastal areas of the Bohai Sea and the Yellow Sea. Severe seawater intrusion is mainly distributed in some coastal areas of Liaoning and Hebei. The intrusion of sea water caused the deterioration of groundwater quality, affected the supply of water resources, and increased the vulnerability of the local water resources system. Scientifically assessing the vulnerability of the water resources system in the Yellow and Bohai Sea coastal areas under seawater intrusion and seeking a proactive water resource management model are of great practical significance for

\footnotetext{
"Corresponding author: qiulei@hhu.edu.cn
} 
preventing the further expansion of seawater intrusion and promoting the sustainable development of the local economy and society.

According to the connotation and methods of vulnerability, domestic and foreign experts and scholars have proposed a variety of evaluation indicators and models for water vulnerability. Polsky [1] constructed a VSD(Vulnerability Scoping Diagram) model based on " exposure-sensitivity -adaptive capacity", starting from these three dimensions to providing new ideas for vulnerability assessment. Kyung [2] take climate change into account to study watershed risk with hydrological vulnerability, constructs an indicator system with DPSIR, uses TOPSIS to calculate the index, and obtains a method to quantify hydrological vulnerability. $\operatorname{Lin}^{[3]}$ constructed an assessment of water resources vulnerability in the Pearl River Delta under a changing environment based on the VSD model. Liu and Zhi [4-5] constructed an index system of groundwater pollution vulnerability and water resources vulnerability of river basins based on the entropy method, and calculated the water resource vulnerability index. Based on the basic theories of water resources vulnerability and the conditions of the Yellow and Bohai Sea coastal areas, this paper focuses on the problem of seawater intrusion, empirically analyses the water resources vulnerability of Longkou City. The evaluation index system of water resource vulnerability based on VSD model was established. The entropy-TOPSIS method was used to evaluate the vulnerability, which provided decision support for water resource management in the coastal areas of the Yellow Sea and Bohai Sea.

\section{Construction of water resource vulnerability assessment index system in the coastal areas of the Yellow Sea and Bohai Sea}

Based on the framework of VSD [1], water resource vulnerability is understood as a function of exposure, sensitivity and adaptive capacity. The negative effects of water resource exposure and sensitivity will increase the degree of system vulnerability. Adaptive capacity is able to relieve the pressure brought by the negative impacts of economic society and ecological environment, so as to improve the system of risk resistance and reduce the vulnerability of water resources. According to the connotation of water resource vulnerability and the VSD model, the vulnerability is divided into three subdimensions. The vulnerability assessment index system of "exposures-sensitivity- adaptive capacity " of water resources under the seawater intrusion is constructed, as is shown in Figure 1. 


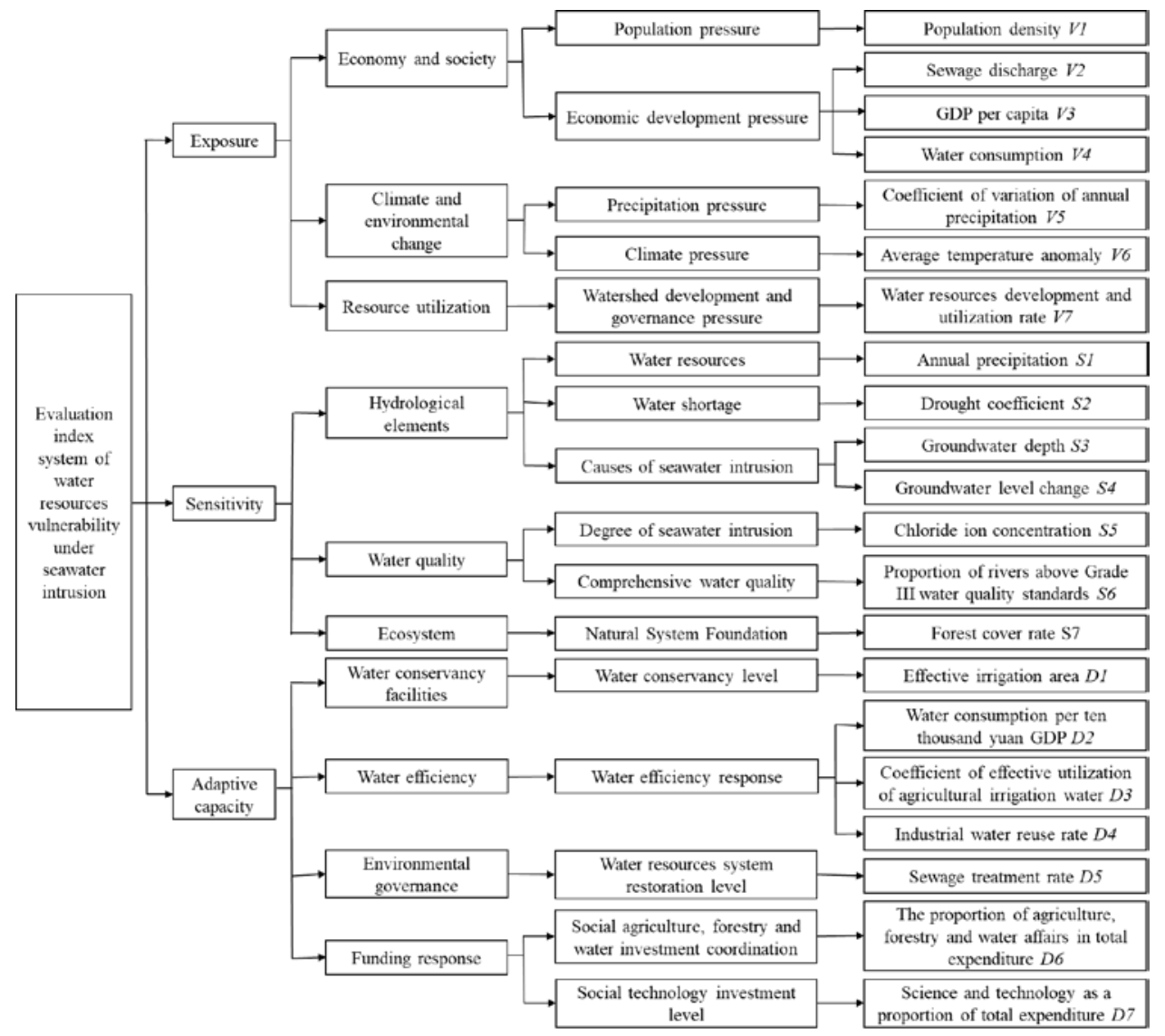

Fig. 1. Evaluation index system of water resources vulnerability under seawater intrusion

\section{Evaluation method of water resources vulnerability based on entropy-TOPSIS}

In the face of the pressure brought by uncertain factors such as economic society and natural environment, water resource vulnerability often has the trend of uncertainty and randomness. In this paper, entropy method and TOPSIS method are selected to evaluate water resource vulnerability, which can objectively analyse and evaluate water resource vulnerability. It can also highlight the impact of the relative variation range of different indicators on water resource vulnerability.

(1) Entropy method was used to calculate the index weight $\boldsymbol{W}$ of water resource vulnerability assessment;

(2) Suppose there are $\boldsymbol{m}$ evaluation objects, and each evaluation object has $\boldsymbol{n}$ indicators. Calculate the weight set of each index $R=\left(r_{i j}\right)_{m n}$, where $C$ is the evaluation index matrix after standardization, $i=1, \ldots, m, j=1, \ldots, n$ :

$$
R=C \times W
$$

(3) According to the index weight set $\boldsymbol{R}$, positive ideal solutions $\boldsymbol{Q}^{+}$and negative ideal solutions $\boldsymbol{Q}^{-}$are determined, where: 


$$
\begin{aligned}
& Q^{+}=\left(r_{1}^{+}, r_{2}^{+}, \ldots, r_{n}^{+}\right) \\
& Q^{-}=\left(r_{1}^{-}, r_{2}^{-}, \ldots, r_{n}^{-}\right)
\end{aligned}
$$

(4) Calculate the distance scale, calculate the distance from each target to the positive ideal solution $\boldsymbol{Q}^{+}$and the negative ideal solution $\boldsymbol{Q}^{-}$. The distance scale can be calculated by the $\boldsymbol{n}$ dimensional Euclidian distance.

$$
\begin{aligned}
& D_{i}^{+}=\sqrt{\sum_{j=1}^{n}\left(r_{i j}-r_{i}^{+}\right)^{2}} \quad i=1,2, \ldots, m \\
& D_{i}^{-}=\sqrt{\sum_{j=1}^{n}\left(r_{i j}-r_{i}^{-}\right)^{2}} \quad i=1,2, \ldots, m
\end{aligned}
$$

(5) In this paper, the positive ideal solution represents the non-vulnerability of the system, while the negative ideal solution represents the vulnerability of the system. Therefore, the relative closeness between the evaluation object and the worst evaluation set is calculated to represent the vulnerability degree of the system:

$$
H_{i}=\frac{D_{i}^{+}}{D_{i}^{+}+D_{i}^{-}} \quad i=1,2, \ldots, m
$$

In the formula: $\boldsymbol{H}_{\boldsymbol{i}} \in[0,1]$, the greater the $\boldsymbol{H}_{\boldsymbol{i}}$ value of the evaluation object, the greater the vulnerability of the evaluation object.

(6) The vulnerability of the system measured by equal weight method

Water resource vulnerability $\boldsymbol{R}_{\boldsymbol{i}}$ is determined by three dimensions of "exposures-sensitivity- adaptive capacity ". It is determined by equal weights of $\boldsymbol{S} \boldsymbol{1}, \boldsymbol{S} \boldsymbol{2}$ and $\boldsymbol{S} 3$ and add up to 1[6]. The higher the $\boldsymbol{R}_{\boldsymbol{i}}$ value is, the higher the water resource system vulnerability is, the weaker its adaptability to the external environment is.

$$
R_{i}=S_{1} H_{i 1}+S_{2} H_{i 2}+S_{3} H_{i 3} \quad i=1,2, \ldots, m
$$
1.

(7) The water resource vulnerability was divided into four levels, as is shown in Table 
Table 1. Water resource vulnerability classification

\begin{tabular}{lll}
\hline $\begin{array}{l}\text { Water resource } \\
\text { vulnerability } \\
\text { range }\end{array}$ & level & Characteristics of water resources system \\
\hline $0.00 \leq \boldsymbol{R}_{\boldsymbol{i}}<0.25$ & $\begin{array}{l}\text { Mildly } \\
\text { vulnerable }\end{array}$ & $\begin{array}{l}\text { The water resources system has strong ability to resist } \\
\text { external influences, strong self-recovery abilityand low } \\
\text { seawater intrusion degree. } \\
\text { The water resources system's ability to resist external } \\
\text { influences is weak. The intrusion degree of seawater is } \\
\text { general. It is close to the threshold value under external } \\
\text { pressure, so it is not easy to recover itself. } \\
\text { The water resource system is greatly affected by external } \\
\text { pressure and the seawater intrusion is more serious. It is } \\
\text { difficult to recover after damage. } \\
\text { The water resource system is difficult to resist the } \\
\text { influence of external pressure. The seawater intrusion is } \\
\text { serious and the recovery after the damage is extremely } \\
\text { difficult, even irreversible. }\end{array}$ \\
\hline $\begin{array}{l}\text { Moderately } \\
0.50 \leq \boldsymbol{R}_{\boldsymbol{i}}<0.75\end{array}$ & $\begin{array}{l}\text { strong } \\
\text { vulnerable }\end{array}$ \\
\hline
\end{tabular}

\section{Empirical study}

Longkou City is located in the northeast of Shandong Province and the northwest of Jiaodong Peninsula, with a large terrain slope. The utilization rate of surface water in Longkou is $55 \%$, far exceeding the internationally recognized upper limit of $40 \%$, and the utilization rate of underground water is $108 \%$, which is seriously overdrawn [7].

Seawater intrusion in Longkou City developed rapidly in 1980, and once developed into a geological disaster with wide distribution and great influence, which caused damage to economic development and social production. This paper evaluates the water resource vulnerability degree of Longkou City. The main relevant data are mainly from Longkou Statistical Yearbook (2009-2018)[8] and Longkou Water Resources Bulletin (2008-2017)[9]. The relevant data, such as ground water level and groundwater depth, are from the monitoring data of various monitoring stations. According to the entropy-TOPSIS evaluation method, combined with the economic, social and natural resources of Longkou City, the vulnerability degree of water resources system in Longkou City from 2008 to 2017 and the change trend of the vulnerability degree of the three dimensions of "exposure-sensitivity - adaptive capacity " were obtained, as is shown in Figure 2. 

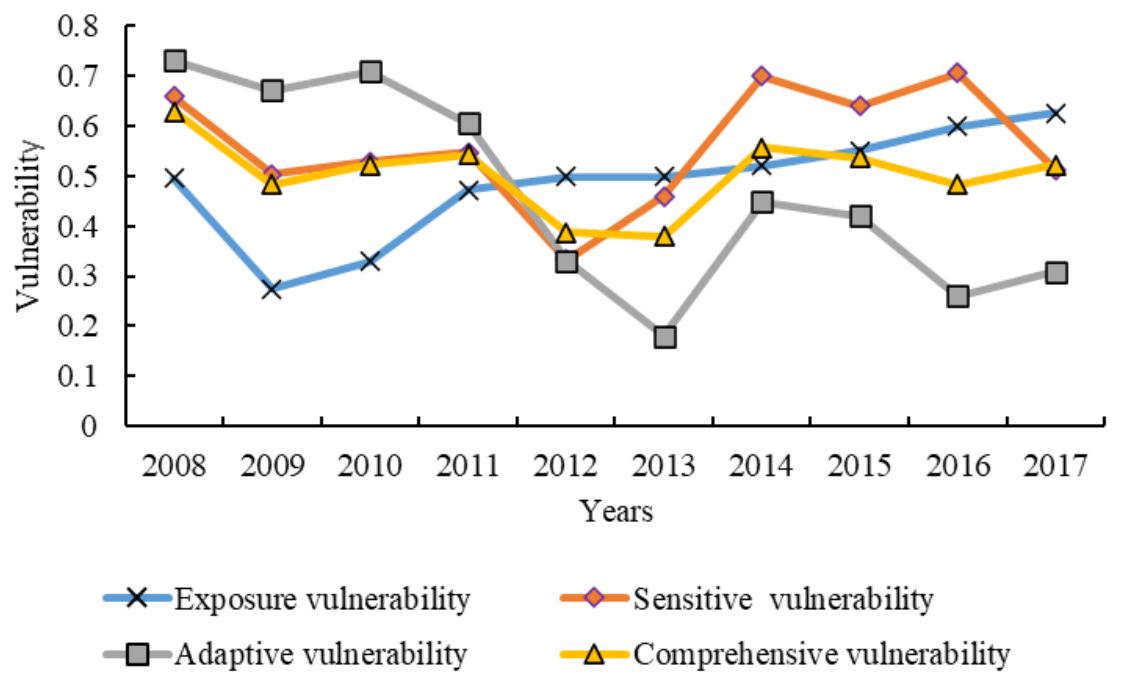

Fig. 2. Vulnerability of water resources system and criterion layer in Longkou City

Analyze the three dimensions vulnerability and comprehensive vulnerability of water resources system in Longkou City, and draw the following conclusions:

(1) Due to the intensification of human activities and the change of natural environment, the system pressure increases significantly. Population density, per capita GDP, temperature and precipitation change are the main factors of the system pressure. (2) Water resources system is sensitive to groundwater level, chloride concentration and other stimuli. (3) With the improvement of water use efficiency and the increase of scientific and technological investment, the adaptability of water resources system in Longkou City was significantly enhanced. (4) The water resource system of Longkou City as a whole is at the level of strong vulnerability.

\section{Conclusions and suggestions}

Based on the basic theory of water resource vulnerability, this paper constructed the evaluation index system of water resource vulnerability under seawater intrusion in the coastal areas of the Yellow Sea and Bohai Sea and combined with the entropy-TOPSIS method to evaluate the water resource vulnerability of Longkou City. The empirical results show that the overall system vulnerability of water resources in Longkou City from 2008 to 2017 is basically at the moderate-strong level under the joint influence of the changes of exposure, sensitivity and adaptive capacity. High population density, rapid economic development, changes in temperature and precipitation are the main causes of system stress. The development of economy, science and technology, improvement of water resources management ability, ecological governance and other adaptive measures have obvious effects on alleviating system vulnerability.

In order to deal with seawater intrusion and alleviate water resource vulnerability, the policy recommendations of water resource adaptive management in Longkou City are proposed as follows: (1) Increase scientific research investment and improve water use efficiency. (2) Adjust the industrial structure, strictly limit and upgrade the scale and number of enterprises in groundwater over-exploitation areas. (3) Use projects such as the South-North Water Diversion Project and seawater desalination to increase the available water supply, control the amount of groundwater extraction, and build a water-saving society. 


\section{Acknowledgments}

This research was supported by National Key R\&D Program of China, Comprehensive prevention and management of seawater intrusion in the coastal area of the Yellow Sea and Bohai Sea (Grant number:2016YFC0402808)

\section{References}

[1] C. Polsky, R. Neff and B. Yarnal, Global Environmental Change, 17 3-4(2007)

[2] S.J. Kyung, C. Eun-Sung, S. Jin-Young and S.L. Kil, Science of the Total Environment, 409 24(2011)

[3] Z. Lin, B. Liu, Y. Wu and S. Peng, Acta Scientiarum Naturalium Universitatis Sunyatseni, 57 8-16(2018)

[4] Q. Liu and Y. Chen, Journal of Yangtze River Scientific Research Institute, 33 10-17(2016)

[5] L. Zhi and H. Xue, Bulletin of Soil and Water Conservation, 38 322-329(2018)

[6] C. Li, H. Wang, J. Tong and S. Liu, Resources Science, 36 84-93(2014)

[7] Y. Shan and L. Wu, Shandong Water Resources, 04 36-37(2013)

[8] Longkou Bureau of Statistics, Longkou Statistical Yearbook (2009-2018)

[9] Longkou Water Resources Bureau, Longkou Water Resources Bulletin (2008-2017 